\title{
CORRECTION
}

\section{Correction to: Primary standardization of the massic activity of a ${ }^{233} \mathrm{~Pa}$ solution}

\author{
R. Fitzgerald ${ }^{1} \cdot$ L. Pibida ${ }^{1}$
}

Published online: 15 March 2019

○) Akadémiai Kiadó, Budapest, Hungary 2019

\section{Correction to: Journal of Radioanalytical and Nuclear Chemistry (2018) 318:149-155 https://doi.org/10.1007/s10967-018-6113-9}

In the original publication, the value " $2.361 \cdot 10^{4} \mathrm{~Bq} \mathrm{~g}^{-1}$ " in the sentence "The final LTAC ${ }^{233} \mathrm{~Pa}$ massic activity at the reference time of 27 June 2017 15:50 PDT was 2.361·10 ${ }^{4} \mathrm{~Bq}$ $\mathrm{g}^{-1}$ with a combined standard uncertainty of $0.33 \%$." under the heading " $4 \pi \beta-\gamma$ anticoincidence measurements" should be read as " $2.632 \cdot 10^{4} \mathrm{~Bq} \mathrm{~g}^{-1}$ ".

Also, in the original publication, the value " $1.471 \cdot 10^{-10}$, in the sentence "By combining the $4 \pi \beta-\gamma$ anticoincidence result with the evaluated half-life of ${ }^{233} \mathrm{~Pa}(26.98 \pm 0.02) \mathrm{d}$, and Avogadro's number, we obtain a concentration of the measured ${ }^{233} \mathrm{~Pa}$ atom mole concentration at the reference date of $1.471 \cdot 10^{-10} \mathrm{~mol} / \mathrm{kg}$ with a combined standard uncertainty of $0.34 \%$." under the heading "Discussion" should be read as " $1.470 \cdot 10^{-10} \mathrm{~mol} / \mathrm{kg}$ ".

Publisher's Note Springer Nature remains neutral with regard to jurisdictional claims in published maps and institutional affiliations.
The original article can be found online at https://doi.org/10.1007/ s10967-018-6113-9.

\section{R. Fitzgerald}

ryan.fitzgerald@nist.gov

1 NIST, 100 Bureau Drive, Gaithersburg, MD 20899, USA 